\title{
Identifying Associations Between Quality of Life Outcomes and Healthcare- Related Variables Among Colorectal Cancer Survivors: A Cross-Sectional Survey Study
}

Dr Amanda Drury ${ }^{1}$, Professor Sheila Payne ${ }^{2}$, Professor Anne-Marie Brady ${ }^{3}$

${ }^{1}$ Postdoctoral Researcher, School of Nursing \& Midwifery, Faculty of Health Sciences, Trinity College Dublin, 24 D'Olier Street, Dublin 2, Ireland, D02 T283. amdrury@tcd.ie Twitter: @druryal.

${ }^{2}$ Emeritus Professor, International Observatory on End of Life Care, Division of Health Research, Lancaster University, Lancaster, UK. s.a.payne@lancaster.ac.uk

${ }^{3}$ Chair of Nursing and Chronic Illness, School of Nursing \& Midwifery, Faculty of Health Sciences, Trinity College Dublin, 24 D'Olier Street, Dublin 2, Ireland, D02 T283. abrady4@tcd.ie

Please cite this paper as:

Drury, A., Payne, S., Brady, A.M. (2019). Identifying Associations Between Quality of Life Outcomes and Healthcare-Related Variables Among Colorectal Cancer Survivors: A Cross-Sectional Survey Study. International Journal of Nursing Studies. DOI: https://doi.org/10.1016/j.ijnurstu.2019.103434.

\section{Corresponding Author:}

Amanda Drury, School of Nursing \& Midwifery, Faculty of Health Sciences, Trinity College Dublin, 24 D'Olier Street, Dublin 2, Ireland, D02 T283.

E-mail: amdrury@tcd.ie

Telephone: 00-353-(0)-1-896-4164. Fax: 00-353-(0)-1-896-3001.

This is the Accepted Manuscript of an article published by Elsevier in the International Journal of Nursing Studies on September 13th, 2019. The Version of Record of this manuscript is available online: DOI: https://doi.org/10.1016/j.ijnurstu.2019.103434. 
Authors Original Manuscript, accepted for publication in the International Journal of Nursing Studies on September $13^{\text {th }}, 2019$.

\begin{abstract}
Background

Follow-up care and surveillance are essential components of colorectal cancer survivorship.

However, the relative contribution of healthcare experiences to quality of life in cancer survivorship is poorly understood.
\end{abstract}

\title{
Objectives
}

This study explores associations between colorectal cancer survivors' healthcare experiences and quality of life.

\section{Design}

Cross-sectional survey study.

\section{Settings}

Participants were recruited from three hospitals, and twenty-one cancer support centres providing psycho-social care to cancer patients and survivors in Ireland.

\section{Participants}

304 colorectal cancer survivors between 6-60 months post-diagnosis.

\section{Methods}

Participants completed a cross-sectional questionnaire, including the Functional Assessment of Therapy-Colorectal Cancer Survey and the Patient Continuity of Care Questionnaire. Multivariate logistic regression analysis was undertaken to identify associations between quality of life outcomes and healthcare-related variables including continuity of care, access to care, information needs and perceptions of support from health and advocacy services.

\section{Results}

Most participants (80\%) had access to a named healthcare professional and were more frequently satisfied with support received in hospital (95\%) compared to primary care $(76 \%)$ or community (61\%) settings. More than two-thirds of participants reported unmet information needs (68\%) or social difficulties (66\%). $40 \%$ reported some dissatisfaction with continuity of care. Greater social difficulty was consistently associated with poorer quality of life in all domains (OR Range: 2.9-9.7). Lower satisfaction with continuity of care predicted poorer physical $(O R=2.6)$, social $(O R=2.1)$, functional $(O R=2.9)$ and overall quality of life $(O R=2.0)$. Unmet information needs $(O R=2.9)$ and absence of access to a named nurse $(O R=3.8)$ were associated with lower levels of emotional wellbeing. Survivors who were living with active malignant disease $(O R=3.8)$, had undergone reversal of a 
Authors Original Manuscript, accepted for publication in the International Journal of Nursing Studies on September 13 $3^{\text {th }}, 2019$.

temporary ostomy $(O R=4.0)$ or had accessed advocacy-led cancer support were more likely to experience lower quality of life overall $(O R=2.6)$.

\section{Conclusions}

Colorectal cancer survivors relied on oncology professionals for cancer-related support and experienced quality of life issues and unmet needs, which were not addressed by oncology, primary care or advocacy professionals. This study suggests there is scope to optimise the contribution of primary care, community care and advocacy services to cancer survivorship care; these services were often overlooked or provided insufficient support when accessed by survivors. The recurring associations between quality of life outcomes and continuity of care and social difficulties suggest these may be meaningful variables to target in the development of interventions to improve survivors' quality of life in the context of healthcare.

\section{Keywords}

Cancer survivorship; colorectal cancer; continuity of care; healthcare; quality of life; unmet needs. 
Authors Original Manuscript, accepted for publication in the International Journal of Nursing Studies on September 13 $3^{\text {th }}, 2019$.

\section{Contribution of Paper}

\section{What is Already Known About this Topic}

- Fragmentation of follow-up care may exacerbate cancer survivors' unmet needs and psychological distress.

- Insufficient continuity of care, informational insecurity and difficulties accessing cancerrelated support contribute to survivors' difficulties with healthcare navigation and may lead to survivors experiencing isolation and a loss of confidence in healthcare providers.

- While quality of life has been identified as a predictor of continuity of care in primary careled models of cancer survivorship care, there is a limited understanding of the impact of healthcare-related factors on quality of life outcomes.

\section{What this Paper Adds}

- Healthcare variables are significantly associated with colorectal cancer survivors' quality of life in multiple domains.

- Poorer continuity of care, difficulties accessing information and support and greater social difficulty were associated with lower quality of life in several domains.

- Hospital-based professionals were the most common source of information and support for colorectal cancer survivors.

- Fewer participants expressed satisfaction with support from primary care and community care professionals.

This is the Accepted Manuscript of an article published by Elsevier in the International Journal of Nursing Studies on September 13th, 2019. The Version of Record of this manuscript is available online: DOI: https://doi.org/10.1016/j.ijnurstu.2019.103434. 
Authors Original Manuscript, accepted for publication in the International Journal of Nursing Studies on September 13 $3^{\text {th }}, 2019$.

\section{Introduction}

Improving cancer survivorship care and quality of life outcomes for cancer survivors were major strategic goals of the Institute of Medicine (2006). While it is evident that colorectal cancer survivors' quality of life may improve over time, a substantial proportion may experience distressing cancer-related symptoms up to ten years following treatment, including bowel dysfunction, sexual dysfunction and peripheral neuropathy (Drury et al., 2017, Harrington et al., 2010).

Follow-up healthcare is a critical component of colorectal cancer survivorship, essential to the management of chronic treatment effects and surveillance of malignant disease. However, increasing time intervals between consultations with healthcare professionals during follow-up has been associated with psychological distress, fear of recurrence and unmet information and supportive care needs among cancer survivors (Beech et al., 2012, Johansson et al., 2014, Taylor et al., 2011). Further challenges to survivors' well-being are differences between healthcare professionals' and survivors' perceptions of their healthcare needs and symptom experiences (Di Fabio et al., 2008) and cancer survivors' reluctance to seek support for cancer-related concerns between surveillance appointments (Beech et al., 2012, Nikoletti et al., 2008).

Quality of life has varying meanings for individuals and groups and is broadly conceptualised as an individuals' perception of their physical, functional, psychological and social well-being in relation to their concerns, goals, expectations, culture, context and values (Cella et al., 1993, The WHOQOL Group, 1995). The Ashing-Giwa (2005) Contextual Model of Health-Related Quality of Life recognises that healthcare is a determining factor for cancer survivors' quality of life outcomes, alongside demographic, socio-ecological and cultural factors. However, the development and validation of the Ashing-Giwa (2005) Model was primarily informed by research with female cancer survivors diagnosed with breast and cervical cancer from multicultural and medically underserved populations (Ashing-Giwa and Lim, 2011, Ashing-Giwa and Lim, 2008, Ashing-Giwa et al., 2009). Few studies explicitly explore the relative influence of healthcare experiences upon quality of life outcomes in colorectal cancer survivorship, or with cancer survivors who are male, or from other ethnic and cultural groups (Drury et al., 2017, Sisler et al., 2012).

Much of the evidence describing the impact of healthcare experiences upon quality of life outcomes in colorectal cancer survivorship is qualitative in nature, and conducted in countries such as the United States or the United Kingdom which have either predominantly privatized or universal healthcare systems (Appleton et al., 2013, Beech et al., 2012, McCaughan et al., 2012, McMullen et al., 2008, Ramirez et al., 2009, Sun et al., 2014, Taylor et al., 2011). In addition, few studies specify whether healthcare experiences contribute to differences in quality of life outcomes in cancer

This is the Accepted Manuscript of an article published by Elsevier in the International Journal of Nursing Studies on September 13th, 2019. The Version of Record of this manuscript is available online: DOI: https://doi.org/10.1016/j.ijnurstu.2019.103434. 
Authors Original Manuscript, accepted for publication in the International Journal of Nursing Studies on September 13 $3^{\text {th }}, 2019$.

survivorship, and do not consider the potential implications of insurance status or models of survivorship care which may contribute to disparities in cancer survivors' access to care and outcomes (Haggstrom et al., 2009, McDougall et al., 2019, O'Shea and Collins, 2016). Ireland operates a mixed public-private model of healthcare provision. Surveillance programmes for colorectal cancer in private healthcare settings are predominantly physician-led, while nurse-led models are increasingly being used in public hospital settings.

The dynamic of the relationship between healthcare professionals and colorectal cancer survivors may influence survivors' recovery, and by extension, their quality of life (Beech et al., 2012, Drury et al., 2017, Johansson et al., 2014, Sun et al., 2014, Taylor et al., 2011). Continuity of care may enhance healthcare professionals' awareness of survivors' healthcare needs, supporting appropriate healthcare navigation for cancer survivors and fostering access to timely and appropriate support when required (Johansson et al., 2014, McMullen et al., 2008, Sun et al., 2014). Access to specialist oncology support may reduce cancer survivors' fear of recurrence and enhance adaptation and recovery in cancer survivorship (Appleton et al., 2013, Taylor et al., 2011). One cross-sectional study suggested quality of life is an important determinant of colorectal cancer survivors' perceptions of continuity of care (Sisler et al., 2012). However, Sisler et al. (2012) included a sample of 106 individuals receiving cancer follow-up care led by primary care practitioners, which may limit the generalizability of findings, as primary care-led follow-up is not a widely used model of care for cancer survivorship internationally. Furthermore, the conclusions of Sisler et al. (2012) suggest that the relationship between continuity of care and quality of life is unidirectional; that those who may require support to address quality of life concerns are less likely to pursue such support from their healthcare provider. Such logic implies that cancer survivors have control over the continuity of their care, and overlooks the potential difficulties of accessing care and information. Consequently, there is a risk that shortcomings in cancer survivors' continuity of care may be conflated with a belief that cancer survivors with poorer quality of life fail to utilise accessible healthcare services to address their concerns, rather than consider the possibility that healthcare services are insufficiently resourced or prepared to address quality of life issues among cancer survivors.

As an emerging concept in the cancer survivorship literature, continuity of care seems to have a role in cancer survivors' unmet need and subsequent quality of life outcomes. However, the scarcity of published evidence makes it difficult to ascertain the nature of the interaction between healthcare experiences and quality of life, and the factors which may influence this interaction. There is a limited understanding of the concept of continuity of care in settings where healthcare is delivered via models which deviate from universal or privatised healthcare systems, such as the mixed public-

This is the Accepted Manuscript of an article published by Elsevier in the International Journal of Nursing Studies on September 13th, 2019. The Version of Record of this manuscript is available online: DOI: https://doi.org/10.1016/j.ijnurstu.2019.103434. 
Authors Original Manuscript, accepted for publication in the International Journal of Nursing Studies on September 13 $3^{\text {th }}, 2019$.

private model of healthcare provision operated in Ireland. Most critically, the assertion that lower satisfaction with continuity of care is predicted by poorer quality of life (Sisler et al., 2012) does not provide an effective explanation of the relationship between cancer survivors' healthcare experiences and quality of life outcomes. Therefore, using the Ashing-Giwa (2005) Contextual Model of Health-Related Quality of Life as a theoretical framework, this study aims to identify the multivariate associations between colorectal cancer survivors' quality of life and healthcare experiences up to five years following diagnosis.

\section{Materials and Methods}

\section{Design and Participants}

This cross-sectional survey study forms part of The Cost of Survival Study, a sequential explanatory mixed methods study. The point at which one becomes a cancer survivor has been widely debated and varies internationally (Doyle, 2008, Drury et al., 2017, Khan et al., 2012, Leigh, 2007, Mullen, 1985, Reuben, 2004, Rowland et al., 2013). The most consistent and accepted definition of cancer survivorship begins at the point of diagnosis, as the challenges of survivorship persist for the duration of the individuals' life, through periods of remission and recurrence (Institute of Medicine, 2006, Reuben, 2004). Colorectal cancer survivors engaged in processes of cancer surveillance and follow up care were the target population for this study. In keeping with the Institute of Medicine (2006) definition, colorectal cancer survivors of all disease stages, 6-60 months post-diagnosis, $\geq 18$ years old, resident in Ireland, able to speak, read, and write in English, and able to provide written, informed consent were eligible to participate in the study. While colorectal cancer survivors' disease status did not influence their eligibility to participate, those who were less than six months postdiagnosis or receiving primary cancer treatments were excluded to ensure that the study represented the quality of life and experiences of those enrolled in cancer surveillance and follow up care pathways.

Survey participants were consecutively recruited to the study between October 2014 and January 2016 via surgical and medical oncology clinics in three hospitals representing the publicly- and privately-funded healthcare settings in Ireland, and 21 voluntary cancer support centers which are designated providers of psychosocial support during and after cancer treatment. A recruitment pack, including the questionnaire, was given to all eligible colorectal cancer survivors attending follow-up appointments; therefore, a formal sample size calculation was not undertaken. This study received ethical approval from the Research Ethics Committees of the university and participating hospitals.

This is the Accepted Manuscript of an article published by Elsevier in the International Journal of Nursing Studies on September 13th, 2019. The Version of Record of this manuscript is available online: DOI: https://doi.org/10.1016/j.ijnurstu.2019.103434. 
Authors Original Manuscript, accepted for publication in the International Journal of Nursing Studies on September 13 $3^{\text {th }}, 2019$.

\section{Data Collection}

Physical, social, emotional, functional, colorectal cancer and overall quality of life was assessed using the 36-item Functional Assessment of Chronic Illness Therapy-Colorectal (FACT-C) questionnaire (Ward et al., 1999). The FACT-C contains five subscales, Physical Well-being (7 items), Social Wellbeing ( 7 items), Emotional Well-being (6 items), Functional Well-being ( 7 items) and the Colorectal Cancer Subscale (7 items). FACT-C items are assessed using a five-point Likert-scale, with item scores ranging from 0 , not at all to 4, very much. Items may be summed to obtain scores for each subscale. An overall FACT-C score is calculated from the sum of all five subscales, which has a possible range of 0-136; higher scores reflect better quality of life (Ward et al., 1999). The FACT-C survey has undergone significant psychometric testing and has demonstrated acceptable internal consistency (Physical $\alpha=0.80$; Social $\alpha=0.71$; Emotional $\alpha=0.75$; Functional $\alpha=0.79$; Colorectal Cancer Concerns $\alpha=0.76$; FACT-C $\alpha=0.81$ ) (Ward et al., 1999).

Continuity of care was evaluated using the Patient Continuity of Care Questionnaire (PCCQ) (Hadjistavropoulos et al., 2008). The PCCQ is a 25 -item self-report questionnaire which may be used to identify negative perceptions interfering with relational, informational and management continuity in healthcare (Hadjistavropoulos et al. 2008). The PCCQ consists of six subscales, Relationships in Hospital (7 items), Information Transfer (5 items), Relationships with Healthcare Providers ( 4 items), Management of Forms ( 3 items), Management of Follow-up ( 3 items) and Management of Communication Among Providers ( 3 items). As the current study aimed to explore follow-up experiences of colorectal cancer survivors up to five years after treatment, the Relationships in Hospital subscale, which addresses experiences as an in-patient, was excluded from the questionnaire. This 18-item version of the PCCQ instrument used in this study was previously used to operationalise Continuity of Care among colorectal cancer survivors in a previous study by Sisler et al. (2012). PCCQ items are evaluated on a five-point Likert scale, with items scores ranging from 1, strongly disagree, to 5, strongly agree. Items are summed and averaged to obtain scores for each subscale (range: 1-5). Similarly, an overall score for continuity of care may be calculated and summed based on the 18 items of the PCCQ (CC-18). Higher scores on all subscales reflect better perceptions of continuity of care. The 18-item PCCQ has demonstrated acceptable internal consistency, with alpha coefficients of 0.78-0.83 (Sisler et al., 2012).

Colorectal cancer survivors' social difficulties were measured using the Social Difficulties Inventory (SDI) (Wright et al., 2011). The SDI consists of 21 Likert scale items with responses ranging from 0 , no difficulty to 3 , very much. It contains subscales to assess social difficulties in three domains; 1 ) Everyday Living (6 items), 2) Money Matters (5 items) and 3) Self and Others (5 items). The SDI also

This is the Accepted Manuscript of an article published by Elsevier in the International Journal of Nursing Studies on September 13th, 2019. The Version of Record of this manuscript is available online: DOI: https://doi.org/10.1016/j.ijnurstu.2019.103434. 
Authors Original Manuscript, accepted for publication in the International Journal of Nursing Studies on September 13 $3^{\text {th }}, 2019$.

has a group of miscellaneous items, which evaluate additional social difficulties, including family planning and living conditions. An overall Social Distress score (SD-16) may be calculated from the sum of these subscales (16 items, range 0-44) (Wright et al. 2011). Higher scores indicate greater distress, and an SD-16 score of $\geq 10$ is indicative of clinically significant social distress (Wright et al. 2007). The SDI has demonstrated acceptable levels of internal consistency (Everyday Living $\alpha=0.85$; Money Matters $\alpha=0.82$; Self and Others $\alpha=0.80$; SD-16 $\alpha=0.89$ ) (Wright et al., 2011).

Participants' perceptions of support from and access to healthcare professionals and information in the aftermath of treatment were evaluated using items from the National Cancer Patient Experience Survey and the Patient Reported Outcome Measures Living with and Beyond Colorectal/GastroIntestinal Cancer Questionnaire in the United Kingdom (Department of Health, United Kingdom 2010, Quality Health, 2012). Two items collected data on cancer survivors' use of cancer support groups (Have you ever attended cancer support group meetings? Response: Yes, No, Don't Know/Can't Remember; Have you attended any other form of cancer support meetings (e.g. counselling, peer-support, other)? Response: Yes, No, Don't Know/Can't Remember). The questionnaire also collected demographic and cancer-related information.

\section{Data Analysis}

SPSS v25 was used to analyse survey data. Quality of life, demographic, health and healthcarerelated variables were descriptively analysed. Quality of life outcomes on the FACT-C and its subscales were positively skewed and violated the assumptions of linear regression analysis; therefore, the FACT-C score was dichotomised using an a priori cut-off of the sample median for each subscale (Table 1). The PCCQ was similarly skewed and was dichotomised in the same manner as Sisler et al. (2012); a score of $>4$ on one or more PCCQ subscales indicated satisfaction with continuity of care. Reporting one or more social difficulties or unmet information needs indicated an issue with each respective variable (Table 1).

\begin{tabular}{|c|c|c|c|}
\hline Original Continuous Variable & $\begin{array}{l}\text { Dichotomous Dependent } \\
\text { Variable }\end{array}$ & Response Level & Dichotomous Interpretation \\
\hline \multirow{2}{*}{$\begin{array}{l}\text { Physical Well-Being Score } \\
\text { (Range: 0-28) }\end{array}$} & \multirow[t]{2}{*}{ Physical Well-Being } & Lower & Score $<26.0$ \\
\hline & & Higher & Score $\geq 26.0$ \\
\hline \multirow{2}{*}{$\begin{array}{l}\text { Social Well-Being Score } \\
\text { (Range: 0-28) }\end{array}$} & \multirow[t]{2}{*}{ Social Well-Being } & Lower & Score $<25.0$ \\
\hline & & Higher & Score $\geq 25.0$ \\
\hline \multirow{2}{*}{$\begin{array}{l}\text { Emotional Well-Being Score } \\
\text { (Range: 0-24) }\end{array}$} & \multirow[t]{2}{*}{ Emotional Well-Being } & Lower & Score $<20.7$ \\
\hline & & Higher & Score $\geq 20.7$ \\
\hline \multirow{2}{*}{$\begin{array}{l}\text { Functional Well-Being Score } \\
\text { (Range: 0-28) }\end{array}$} & \multirow[t]{2}{*}{ Functional Well-Being } & Lower & Score $<23.0$ \\
\hline & & Higher & Score $\geq 23.0$ \\
\hline \multirow{2}{*}{$\begin{array}{l}\text { Colorectal Cancer Concerns Score } \\
\text { (Range: 0-28) }\end{array}$} & \multirow{2}{*}{$\begin{array}{l}\text { Colorectal Cancer } \\
\text { Concerns }\end{array}$} & Lower & Score $<23.0$ \\
\hline & & Higher & Score $\geq 23.0$ \\
\hline \multirow{3}{*}{$\begin{array}{l}\text { FACT - Colorectal Score (FACT-C) } \\
\text { (Range: 0-136) }\end{array}$} & \multirow[t]{3}{*}{ Quality of Life } & Lower & Score $<116.0$ \\
\hline & & Higher & Score $\geq 116.0$ \\
\hline & & Satisfied & All PCCQ subscales score $>4$ \\
\hline
\end{tabular}

This is the Accepted Manuscript of an article published by Elsevier in the International Journal of Nursing Studies on September 13th, 2019. The Version of Record of this manuscript is available online: DOI: https://doi.org/10.1016/j.ijnurstu.2019.103434. 
Authors Original Manuscript, accepted for publication in the International Journal of Nursing Studies on September $13^{\text {th }}, 2019$.

\begin{tabular}{|c|c|c|c|}
\hline $\begin{array}{l}\text { Patient Continuity of Care } \\
\text { Questionnaire (PCCQ) (Range: 1-5) }\end{array}$ & $\begin{array}{l}\text { Level of Satisfaction with } \\
\text { Continuity of Care }\end{array}$ & Some Dissatisfaction & One or more PCCQ subscales score $\leq 4$ \\
\hline \multirow{2}{*}{$\begin{array}{l}\text { Social Difficulties-16 Score (SD-16) } \\
\text { (Range: 0-44) }\end{array}$} & \multirow[t]{2}{*}{ Social Difficulties } & None & SD-16 = 0 \\
\hline & & One or More & SD-16 $\geq 1$ \\
\hline \multirow{2}{*}{$\begin{array}{l}\text { National Cancer Patient } \\
\text { Experience Survey (Range: 0-11) }\end{array}$} & \multirow[t]{2}{*}{ Unmet Information Needs } & None & Unmet Needs $=0$ \\
\hline & & One or More & Unmet Needs $\geq 1$ \\
\hline
\end{tabular}

Table 1: Operational Definitions of Dichotomised Dependent and Independent Variables

Univariate logistic regression was used to determine independent socio-demographic, health-related and healthcare-related factors associated with poorer quality of life on each subscale of the FACT-C. Quality of life was coded as 0, "Higher" or 1, "Lower" quality of life; lower quality of life was the reference value for each of the FACT-C subscales in regression analyses. Reference categories for predictor variables were selected based on the mean FACT-C score for each variable category; the category with the highest overall quality of life score was chosen as the reference group. Backward stepwise elimination was then used to identify suitable logistic regression models for quality of life on all six subscales of the FACT-C (physical, social, emotional, functional, colorectal cancer concerns, overall quality of life). Sociodemographic (age, gender, living circumstances, area of residence, changes in employment status, ethnicity) and health-related variables (diagnosis, time since diagnosis, treatment modalities, disease status, stoma status, comorbidities) which were independently associated with each FACT-C subscale at the level $p \leq 0.20$ were introduced into the respective multivariate model alongside healthcare-related variables. Non-significant terms $(p \leq 0.05)$ were removed at each step of the model-building procedure.

Cases with missing data were excluded on a test-by-test basis. For FACT-C subscales, prorated scores were calculated for missing data where at least $50 \%$ of items were completed; for the FACT-C scale, prorated scores were calculated where at least $80 \%$ of items were completed. For the SDI and PCCQ surveys, prorated scores were calculated where at least $80 \%$ of items were completed.

\section{Results}

\section{Sample Characteristics}

Of 404 colorectal cancer survivors invited to participate in the study, 304 questionnaires were returned (response rate $=75.6 \%$ ). Participants were predominantly White Irish, ranging in age from 25 to 96 years ( $\bar{x}=67.2$ years, $S D=11.4$ ) and diagnosed on average, 3.1 years prior to participation in the study ( $S D=1.4$ ) (Table 2). Most were diagnosed with colon cancer $(64.1 \%, n=191)$ and had no active disease at the time of the survey $(82.9 \%, n=228)$. Almost half held private health insurance $(48.3 \%, n=138)$, and were followed up in a designated cancer centre of excellence $(56.9 \%, n=164)$. Overall, participants reported reasonably positive quality of life on all FACT-C subscales (Table 3 ), with a mean score of 111.9 on the FACT-C $(S D=18.8)$.

This is the Accepted Manuscript of an article published by Elsevier in the International Journal of Nursing Studies on September 13th, 2019. The Version of Record of this manuscript is available online: DOI: https://doi.org/10.1016/j.ijnurstu.2019.103434. 
Authors Original Manuscript, accepted for publication in the International Journal of Nursing Studies on September $13^{\text {th }}, 2019$.

\section{Healthcare Experiences}

Table 4 outlines the participants' responses to healthcare experience items. Most had access to a named nurse $(80.8 \%, n=227)$ or doctor $(79.9 \%, n=226)$ to discuss cancer-related concerns and felt supported by hospital staff in the course of their cancer-related care $(95.1 \%, n=269)$. However, fewer participants felt they were supported by primary care professionals $(76.2 \%, n=215)$ or community services staff $(61.1 \%, n=171) .14 .9 \%$ had accessed support from voluntary cancer support services $(n=42)$. Of participants who felt unsupported by community services or primary care staff, $80.7 \%$ ( $n=88)$ did not believe they needed support from community services, and $29.9 \%$ $(n=20)$ did not believe they required support from primary care professionals. Although not part of standard practice, more than one-quarter of participants believed they had received a cancer treatment summary $(34.6 \%, n=97)$ or cancer survivorship care plan $(26.9 \%, n=76)$. Almost threefifths of participants were satisfied with continuity of care $(59.6 \%, n=161, \bar{x}=4.5, S D=0.8$; Table 3 ). Although most felt supported by and had access to healthcare professionals to discuss cancerrelated concerns, more than two-thirds reported unmet information needs $(67.6 \%, n=184, \bar{x}=2.1$, $S D=2.2$; Table 3 ). One hundred and eighty-six participants reported one or more social difficulties (66.0\%, $\bar{x}=3.9, S D=5.7$; $\underline{\text { Table } 3)}$.

This is the Accepted Manuscript of an article published by Elsevier in the International Journal of Nursing Studies on September 13th, 2019. The Version of Record of this manuscript is available online: DOI: https://doi.org/10.1016/j.ijnurstu.2019.103434. 
Authors Original Manuscript, accepted for publication in the International Journal of Nursing Studies on September $13^{\text {th }}, 2019$.

\begin{tabular}{|c|c|c|c|}
\hline Characteristic & Response & Mean & SD \\
\hline Age $(n=283)$ & & 67.2 & 11.4 \\
\hline \multirow[t]{2}{*}{ Time Since Diagnosis $(n=278)$} & & 3.1 & 1.4 \\
\hline & Sociodemographic Variables & $\mathbf{n}$ & $\%$ \\
\hline \multirow[t]{2}{*}{ Age $(n=283)$} & $<65$ & 93 & 32.9 \\
\hline & $\geq 65$ & 190 & 67.1 \\
\hline \multirow[t]{2}{*}{ Gender $(n=285)$} & Female & 126 & 44.2 \\
\hline & Male & 159 & 55.8 \\
\hline \multirow[t]{2}{*}{ Lives Alone ( $n=284)$} & No & 231 & 81.3 \\
\hline & Yes & 53 & 18.7 \\
\hline \multirow[t]{2}{*}{ Area of Residence ( $n=281$ ) } & Urban & 215 & 76.5 \\
\hline & Rural & 66 & 23.5 \\
\hline \multirow{3}{*}{$\begin{array}{l}\text { Change in Employment Status } \\
\text { Since Diagnosis }(n=284)\end{array}$} & Remained/Became Employed & 71 & 25.0 \\
\hline & Remained Unemployed & 167 & 58.8 \\
\hline & Became Unemployed & 46 & 16.2 \\
\hline \multirow[t]{2}{*}{ Ethnicity ( $n=287$ ) } & Irish & 274 & 95.5 \\
\hline & Other & 13 & 4.5 \\
\hline \multicolumn{4}{|c|}{ Health-Related Variables } \\
\hline \multirow[t]{3}{*}{ Diagnosis ( $n=298$ ) } & Colon & 191 & 64.1 \\
\hline & Rectum & 69 & 23.2 \\
\hline & Other & 38 & 12.8 \\
\hline \multirow[t]{2}{*}{ Time Since Diagnosis ( $n=278$ ) } & $<2$ years & 110 & 39.6 \\
\hline & $\geq 2$ years & 168 & 60.4 \\
\hline \multirow[t]{2}{*}{ Radiotherapy ( $n=300)$} & No Radiotherapy & 228 & 76.0 \\
\hline & Any Radiotherapy & 72 & 24.0 \\
\hline \multirow[t]{2}{*}{ Chemotherapy $(n=300)$} & No Chemotherapy & 125 & 41.7 \\
\hline & Any Chemotherapy & 175 & 58.3 \\
\hline \multirow[t]{2}{*}{ Surgery $(n=300)$} & No Surgery & 26 & 8.7 \\
\hline & Any Surgery & 273 & 91.3 \\
\hline \multirow[t]{2}{*}{ Disease Status ( $n=275)$} & In Remission & 228 & 82.9 \\
\hline & Any Active Disease & 47 & 17.1 \\
\hline \multirow[t]{3}{*}{ Stoma $(n=286)$} & Never had a Stoma & 153 & 53.5 \\
\hline & Stoma Reversed & 78 & 27.3 \\
\hline & Stoma Present & 55 & 19.2 \\
\hline \multirow[t]{2}{*}{ Comorbidities $(n=280)$} & None & 62 & 22.1 \\
\hline & One or More & 218 & 77.9 \\
\hline \multicolumn{4}{|c|}{ Healthcare-Related Variables } \\
\hline \multirow[t]{2}{*}{ Private Health Insurance ( $n=286)$} & Yes & 138 & 48.3 \\
\hline & No & 148 & 51.7 \\
\hline \multirow[t]{3}{*}{ Type of Hospital Attended ( $n=288)$} & Centre of Excellence & 164 & 56.9 \\
\hline & Private & 24 & 8.3 \\
\hline & Regional/Other & 100 & 34.7 \\
\hline
\end{tabular}

Table 2: Sample Characteristics

This is the Accepted Manuscript of an article published by Elsevier in the International Journal of Nursing Studies on September 13th, 2019. The Version of Record of this manuscript is available online: DOI: https://doi.org/10.1016/j.ijnurstu.2019.103434. 
Authors Original Manuscript, accepted for publication in the International Journal of Nursing Studies on September $13^{\text {th }}, 2019$.

\begin{tabular}{|c|c|c|c|c|c|}
\hline Characteristic & Variable & Mean & SD & Median & $\mathbf{N}$ \\
\hline \multirow{6}{*}{ Quality of Life } & Physical Well-Being (Range: 0-28) & 24.6 & 4.3 & 26.0 & 264 \\
\hline & Social Well-Being (Range: 0-28) & 23.3 & 5.4 & 25.0 & 278 \\
\hline & Emotional Well-Being (Range: 0-24) & 20.1 & 3.9 & 20.7 & 276 \\
\hline & Functional Well-Being (Range: 0-28) & 21.2 & 6.6 & 23.0 & 283 \\
\hline & Colorectal Cancer Concerns (Range: 0-28) & 22.1 & 5.0 & 23.0 & 283 \\
\hline & Quality of Life (FACT-C) (Range: 0-136) & 111.9 & 18.8 & 116.0 & 251 \\
\hline \multirow{3}{*}{ Healthcare-Related } & Continuity of Care (CC-18) (Range: 1-5) & 4.5 & 0.8 & 4.8 & 270 \\
\hline & Social Difficulties (SD-16) (Range: 0-44) & 3.9 & 5.7 & 2.0 & 282 \\
\hline & Number of Unmet Information Needs (Range: 0-11) & 2.1 & 2.2 & 2.0 & 272 \\
\hline
\end{tabular}

Table 3: Summary of Quality of Life Outcomes

\begin{tabular}{|c|c|c|c|}
\hline Characteristic & Response & $n$ & $\%$ \\
\hline \multirow{2}{*}{$\begin{array}{l}\text { Level of Satisfaction with Continuity } \\
\text { of Care }(n=270)\end{array}$} & Satisfied & 161 & 59.6 \\
\hline & Some Dissatisfaction & 109 & 40.4 \\
\hline \multirow{2}{*}{ Care Plan ( $n=283)$} & Yes & 76 & 26.9 \\
\hline & No & 207 & 73.1 \\
\hline \multirow{2}{*}{ Treatment Summary ( $n=280)$} & Yes & 97 & 34.6 \\
\hline & No & 183 & 65.4 \\
\hline \multirow{2}{*}{$\begin{array}{l}\text { Access to a Named Nurse for Cancer- } \\
\text { Related Worries }(n=281)\end{array}$} & Yes & 227 & 80.8 \\
\hline & No & 54 & 19.2 \\
\hline \multirow{2}{*}{$\begin{array}{l}\text { Access to a Named Doctor for } \\
\text { Cancer-Related Worries ( } n=283 \text { ) }\end{array}$} & Yes & 226 & 79.9 \\
\hline & No & 57 & 20.1 \\
\hline \multirow{2}{*}{$\begin{array}{l}\text { Feel supported by Hospital Staff } \\
(n=283)\end{array}$} & Yes & 269 & 95.1 \\
\hline & No & 14 & 4.9 \\
\hline \multirow{2}{*}{$\begin{array}{l}\text { Feel Supported by Primary Care } \\
\text { Professional }(n=282)\end{array}$} & Yes & 215 & 76.2 \\
\hline & No & 67 & 23.8 \\
\hline \multirow{2}{*}{$\begin{array}{l}\text { Feel Supported by Community } \\
\text { Services Staff }(n=280)\end{array}$} & Yes & 171 & 61.1 \\
\hline & No & 109 & 38.9 \\
\hline \multirow{2}{*}{$\begin{array}{l}\text { Accessed Voluntary Cancer Support } \\
\text { Services ( } n=281)\end{array}$} & No & 239 & 85.1 \\
\hline & Yes & 42 & 14.9 \\
\hline \multirow{2}{*}{ Social Difficulties ( $n=282$ ) } & None & 96 & 34.0 \\
\hline & One or More & 186 & 66.0 \\
\hline \multirow{2}{*}{ Unmet Information Needs ( $n=272$ ) } & None & 88 & 32.4 \\
\hline & One or More & 184 & 67.6 \\
\hline
\end{tabular}

Table 4: Summary of Responses to Healthcare-Related Items

\section{Multivariable Logistic Regression Models}

Univariate logistic regression analysis identified demographic and health-related factors independently associated with quality of life outcomes on each subscale of the FACT-C (Supplementary Data; Tables A.1 \& A.2). All multivariate models presented in this paper met the assumptions underpinning logistic regression analysis, with no multicollinearity (VIF < 10.0) or outliers identified (studentized residuals $<2.5$ ). All multivariate models reported were significant $(p<$ 0.001), with acceptable goodness of fit statistics (Hosmer-Lemeshow: $p=0.285-0.964$ ), explaining variance ranging between $29.9 \%$ and $43.7 \%$ (Nagelkerke $R^{2}$ ).

Physical Well-being

Social difficulties were most significantly associated with suboptimal physical well-being. Lower satisfaction with continuity of care and absence of a treatment summary were related to poorer

This is the Accepted Manuscript of an article published by Elsevier in the International Journal of Nursing Studies on September 13th, 2019. The Version of Record of this manuscript is available online: DOI: https://doi.org/10.1016/j.ijnurstu.2019.103434. 
Authors Original Manuscript, accepted for publication in the International Journal of Nursing Studies on September 13 $3^{\text {th }}, 2019$.

physical well-being. Satisfaction with support from community services was inversely associated with physical well-being (Table 5).

\begin{tabular}{|c|c|c|c|c|c|c|c|c|}
\hline Characteristic & Predictor & B & SE & Wald & df & $\begin{array}{l}\text { Adjusted } \\
\text { OR }\end{array}$ & $95 \% \mathrm{Cl}$ & $p$ \\
\hline \multirow[t]{3}{*}{ Diagnosis } & Colon & & & 4.987 & 2 & Reference & & 0.083 \\
\hline & Rectum & -0.389 & 0.350 & 1.235 & 1 & 0.7 & $0.3-1.3$ & 0.266 \\
\hline & Other & 0.781 & 0.468 & 2.785 & 1 & 2.2 & $0.9-5.5$ & 0.095 \\
\hline \multirow[t]{2}{*}{ Comorbidities } & None & & & & & \multicolumn{2}{|l|}{ Reference } & \\
\hline & One or More & 0.625 & 0.350 & 3.187 & 1 & 1.9 & $0.9-3.7$ & 0.074 \\
\hline \multirow{2}{*}{$\begin{array}{l}\text { Level of Satisfaction with } \\
\text { Continuity of Care }\end{array}$} & Satisfied & & & & & \multicolumn{2}{|l|}{ Reference } & \\
\hline & Some Dissatisfaction & 0.963 & 0.298 & 10.443 & 1 & 2.6 & $1.5-4.7$ & $0.001^{*}$ \\
\hline \multirow[t]{2}{*}{ Treatment Summary } & Yes & & & & & \multicolumn{2}{|l|}{ Reference } & \\
\hline & No & 0.700 & 0.316 & 4.908 & 1 & 2.0 & $1.1-3.7$ & $0.027^{*}$ \\
\hline \multirow{2}{*}{$\begin{array}{l}\text { Feel Supported by } \\
\text { Community Services Staff }\end{array}$} & Yes & & & & & \multicolumn{2}{|l|}{ Reference } & \\
\hline & No & -0.668 & 0.313 & 4.568 & 1 & 0.5 & $0.3-0.9$ & $0.033^{*}$ \\
\hline \multirow[t]{2}{*}{ Social Difficulties } & None & & & & & \multicolumn{2}{|l|}{ Reference } & \\
\hline & One or More & 1.666 & 0.316 & 27.822 & 1 & 5.3 & $2.8-9.8$ & $<0.001 *$ \\
\hline \multicolumn{9}{|c|}{$*_{\text {indicates statistical significance at } p \leq 0.05}$} \\
\hline \multicolumn{9}{|c|}{ Physical Well-Being Model: $\chi 2(7, n=261)=66.164, p \leq 0.001$} \\
\hline \multicolumn{9}{|c|}{ Hosmer \& Lemeshow Goodness of Fit: X2(7) = 1.927, $p=0.964$} \\
\hline \multicolumn{9}{|c|}{ Cox \& Snell $R^{2}: 22.4 \%$; Nagelkerke $R^{2}: 29.9 \%$; Sensitivity: $74.8 \%$; Specificity: $65.4 \%$} \\
\hline \multicolumn{9}{|c|}{ Receiver Operating Characteristic: 0.778 (95\% Cl: 0.722-0.833) } \\
\hline \multicolumn{9}{|c|}{ Tolerance: 0.910-0.961; VIF: 1.041-1.099 } \\
\hline
\end{tabular}

Table 5: Adjusted Multivariate Predictors of Poorer Outcomes for Physical Well-Being Among Colorectal Cancer Survivors

\section{Social Well-being}

Male participants and those who had undergone a stoma reversal were more likely to report lower social well-being scores. Lower satisfaction with continuity of care and the absence of private health insurance were associated with worse social well-being. Social difficulties were associated with a three-fold increase in the likelihood of poorer social well-being (Table 6).

\begin{tabular}{|c|c|c|c|c|c|c|c|c|}
\hline Characteristic & Predictor & B & SE & Wald & df & $\begin{array}{l}\text { Adjusted } \\
\text { OR }\end{array}$ & $95 \% \mathrm{Cl}$ & $p$ \\
\hline \multirow[t]{2}{*}{ Gender } & Female & & & & & Reference & & \\
\hline & Male & 0.803 & 0.311 & 6.668 & 1 & 2.2 & $1.2-4.1$ & $0.010^{*}$ \\
\hline \multirow[t]{2}{*}{ Disease Status } & In Remission & & & & & Reference & & \\
\hline & Any Active Disease & 0.786 & 0.426 & 3.415 & 1 & 2.2 & $1.0-5.1$ & 0.065 \\
\hline \multirow[t]{3}{*}{ Stoma } & Never had a Stoma & & & 7.349 & 2 & Reference & & $0.025^{*}$ \\
\hline & Stoma Reversed & 0.837 & 0.351 & 5.687 & 1 & 2.3 & $1.2-4.6$ & $0.017^{*}$ \\
\hline & Stoma Present & -0.221 & 0.394 & 0.314 & 1 & 0.8 & $0.4-1.7$ & 0.575 \\
\hline \multirow[t]{2}{*}{ Private Health Insurance } & Yes & & & & & Reference & & \\
\hline & No & 0.668 & 0.299 & 4.989 & 1 & 2.0 & $1.1-3.5$ & $0.026 *$ \\
\hline \multirow{2}{*}{$\begin{array}{l}\text { Level of Satisfaction with } \\
\text { Continuity of Care }\end{array}$} & Satisfied & & & & & Reference & & \\
\hline & Some Dissatisfaction & 0.761 & 0.311 & 5.988 & 1 & 2.1 & $1.2-3.9$ & $0.014^{*}$ \\
\hline \multirow{2}{*}{$\begin{array}{l}\text { Access to a Named Doctor } \\
\text { for Cancer-Related Worries }\end{array}$} & Yes & & & & & Reference & & \\
\hline & No & 0.701 & 0.376 & 3.481 & 1 & 2.0 & $1.0-4.2$ & 0.062 \\
\hline \multirow{2}{*}{$\begin{array}{l}\text { Accessed Voluntary Cancer } \\
\text { Support Services }\end{array}$} & No & & & & & Reference & & \\
\hline & Yes & 0.758 & 0.431 & 3.090 & 1 & 2.1 & $0.9-5.0$ & 0.079 \\
\hline \multirow[t]{2}{*}{ Social Difficulties } & None & & & & & Reference & & \\
\hline & One or More & 1.175 & 0.319 & 13.518 & 1 & 3.2 & $1.7-6.1$ & $<0.001^{*}$ \\
\hline
\end{tabular}

This is the Accepted Manuscript of an article published by Elsevier in the International Journal of Nursing Studies on September 13th, 2019. The Version of Record of this manuscript is available online: DOI: https://doi.org/10.1016/j.ijnurstu.2019.103434. 
Authors Original Manuscript, accepted for publication in the International Journal of Nursing Studies on September $13^{\text {th }}, 2019$.

\begin{tabular}{|c|c|c|c|c|c|c|c|c|}
\hline Characteristic & Predictor & B & SE & Wald & df & $\begin{array}{l}\text { Adjusted } \\
\text { OR }\end{array}$ & $95 \% \mathrm{Cl}$ & $p$ \\
\hline \multicolumn{9}{|c|}{$*_{\text {indicates statistical significance at } p \leq 0.05}$} \\
\hline \multicolumn{9}{|c|}{ Social Well-Being Model: $\chi^{2}(9, n=241)=57.925, p \leq 0.001$} \\
\hline \multicolumn{9}{|c|}{ Hosmer \& Lemeshow Goodness of Fit: $\chi^{2}(8)=4.267, p=0.832$} \\
\hline \multicolumn{9}{|c|}{ Cox \& Snell $R^{2}: 21.4 \%$; Nagelkerke $R^{2}: 28.5 \%$; Sensitivity: $70.7 \%$; Specificity: $68.6 \%$} \\
\hline \multicolumn{9}{|c|}{ Receiver Operating Characteristic: 0.768 (95\% Cl: 0.709-0.827) } \\
\hline \multicolumn{9}{|c|}{ Tolerance: $0.887-0.956$; VIF: $1.046-1.127$} \\
\hline
\end{tabular}

Table 6: Adjusted Multivariate Predictors of Poorer Outcomes for Social Well-Being Among Colorectal Cancer Survivors

\section{Emotional Well-being}

Becoming unemployed and living with active disease were the factors most significantly associated with suboptimal emotional well-being. Female gender, social difficulties and the type of hospital attended for follow-up were related to participants' emotional well-being. Of healthcare-related variables, survivors who did not have access to a named nurse and who reported unmet information needs had a higher likelihood of reporting poorer emotional well-being (Table 7).

\begin{tabular}{|c|c|c|c|c|c|c|c|c|}
\hline Characteristic & Predictor & B & SE & Wald & df & $\begin{array}{l}\text { Adjusted } \\
\text { OR }\end{array}$ & $95 \% \mathrm{Cl}$ & $p$ \\
\hline \multirow[t]{2}{*}{ Age } & $<65$ & & & & & Reference & & \\
\hline & $\geq 65$ & -0.722 & 0.395 & 3.352 & 1 & 0.5 & $0.2-1.1$ & 0.067 \\
\hline \multirow[t]{2}{*}{ Gender } & Female & & & & & Reference & & \\
\hline & Male & -0.731 & 0.317 & 5.304 & 1 & 0.5 & $0.3-0.9$ & $0.021^{*}$ \\
\hline \multirow{3}{*}{$\begin{array}{l}\text { Change in Employment } \\
\text { Status Since Diagnosis }\end{array}$} & Remained/Became Employed & & & 11.252 & 2 & Reference & & $0.004^{*}$ \\
\hline & Remained Unemployed & -0.037 & 0.419 & 0.008 & 1 & 1.0 & $0.4-2.2$ & 0.929 \\
\hline & Became Unemployed & 1.577 & 0.546 & 8.348 & 1 & 4.8 & $1.7-14.1$ & $0.004 *$ \\
\hline \multirow[t]{2}{*}{ Disease Status } & In Remission & & & & & Reference & & \\
\hline & Any Active Disease & 1.259 & 0.449 & 7.865 & 1 & 3.5 & $1.5-8.5$ & $0.005^{*}$ \\
\hline \multirow[t]{2}{*}{ Comorbidities } & None & & & & & Reference & & \\
\hline & One or More & 0.669 & 0.382 & 3.071 & 1 & 2.0 & $0.9-4.1$ & 0.080 \\
\hline \multirow{3}{*}{$\begin{array}{l}\text { Type of Hospital Attended } \\
\text { for Follow-up Care }\end{array}$} & Centre of Excellence & & & 9.167 & 2 & Reference & & $0.010^{*}$ \\
\hline & Private & -2.065 & 0.688 & 9.001 & 1 & 0.1 & $0.0-0.5$ & $0.003^{*}$ \\
\hline & Regional/Other & -0.464 & 0.357 & 1.684 & 1 & 0.6 & $0.3-1.3$ & 0.194 \\
\hline \multirow{2}{*}{$\begin{array}{l}\text { Access to a Named Nurse } \\
\text { for Cancer-Related Worries }\end{array}$} & Yes & & & & & Reference & & \\
\hline & No & 1.331 & 0.466 & 8.159 & 1 & 3.8 & $1.5-9.4$ & $0.004^{*}$ \\
\hline \multirow[t]{2}{*}{ Social Difficulties } & None & & & & & Reference & & \\
\hline & One or More & 0.807 & 0.336 & 5.784 & 1 & 2.2 & $1.2-4.3$ & $0.016^{*}$ \\
\hline \multirow[t]{2}{*}{ Unmet Information Needs } & None & & & & & Reference & & \\
\hline & One or More & 1.054 & 0.340 & 9.605 & 1 & 2.9 & $1.5-5.6$ & $0.002 *$ \\
\hline \multicolumn{9}{|c|}{ *indicates statistical significance at $p \leq 0.05$} \\
\hline \multicolumn{9}{|c|}{ Emotional Well-Being Model: $\chi^{2}(11, n=245)=76.188, p \leq 0.001$} \\
\hline \multicolumn{9}{|c|}{ Hosmer \& Lemeshow Goodness of Fit: $\chi^{2}(8)=3.695, p=0.884$} \\
\hline \multicolumn{9}{|c|}{ Cox \& Snell $R^{2}: 26.7 \%$; Nagelkerke $R^{2}: 35.6 \%$; Sensitivity: $71.2 \%$; Specificity: $75.0 \%$} \\
\hline \multicolumn{9}{|c|}{ Receiver Operating Characteristic: 0.803 (95\% Cl: 0.748-0.858) } \\
\hline \multicolumn{9}{|c|}{ Tolerance: 0.839-0.982; VIF: 1.108-1.192 } \\
\hline
\end{tabular}

Table 7: Adjusted Multivariate Predictors of Poorer Outcomes for Emotional Well-Being Among Colorectal Cancer Survivors

\section{Functional Well-being}

Reversal of stoma and comorbid conditions were significantly associated with poorer functional wellbeing. Social difficulties were strongly related to poorer functional well-being, while poorer

This is the Accepted Manuscript of an article published by Elsevier in the International Journal of Nursing Studies on September 13th, 2019. The Version of Record of this manuscript is available online: DOI: https://doi.org/10.1016/j.ijnurstu.2019.103434. 
Authors Original Manuscript, accepted for publication in the International Journal of Nursing Studies on September 13 $3^{\text {th }}, 2019$.

continuity of care and absence of private health insurance were associated with a two- to three-fold increase in the odds of reporting suboptimal functional well-being (Table 8).

\section{Colorectal Cancer Concerns}

Gender, changed employment status, co-morbid disease, stoma status, treatment with chemotherapy and active malignancy were each associated with poorer colorectal cancer-specific quality of life. Greater social difficulties, absence of private health insurance, and not having access to a named doctor were related to lower colorectal cancer-specific subscale scores (Table 9 ).

\begin{tabular}{|c|c|c|c|c|c|c|c|c|}
\hline Characteristic & Predictor & B & SE & Wald & df & $\begin{array}{l}\text { Adjusted } \\
\text { OR }\end{array}$ & $95 \% \mathrm{Cl}$ & $p$ \\
\hline \multirow[t]{2}{*}{ Ethnicity } & White Irish & & & & & Reference & & \\
\hline & Other & -1.217 & 0.736 & 2.731 & 1 & 0.3 & $0.1-1.3$ & 0.098 \\
\hline \multirow[t]{3}{*}{ Stoma } & Never had a Stoma & & & 4.000 & 2 & Reference & & 0.135 \\
\hline & Stoma Reversed & 0.675 & 0.345 & 3.827 & 1 & 2.0 & $1.0-3.9$ & $0.050 *$ \\
\hline & Stoma Present & 0.377 & 0.388 & 0.945 & 1 & 1.5 & $0.7-3.1$ & 0.331 \\
\hline \multirow[t]{2}{*}{ Comorbidities } & None & & & & & Reference & & \\
\hline & One or More & 0.898 & 0.364 & 6.087 & 1 & 2.5 & $1.2-5.0$ & $0.014^{*}$ \\
\hline \multirow[t]{2}{*}{ Private Health Insurance } & Yes & & & & & Reference & & \\
\hline & No & 0.756 & 0.290 & 6.793 & 1 & 2.1 & $1.2-3.8$ & $0.009 *$ \\
\hline \multirow{2}{*}{$\begin{array}{l}\text { Level of Satisfaction with } \\
\text { Continuity of Care }\end{array}$} & Satisfied & & & & & Reference & & \\
\hline & Some Dissatisfaction & 1.057 & 0.299 & 12.508 & 1 & 2.9 & $1.6-5.2$ & $<0.001^{*}$ \\
\hline \multirow[t]{2}{*}{ Social Difficulties } & None & & & & & Reference & & \\
\hline & One or More & 1.651 & 0.320 & 26.689 & 1 & 5.2 & $2.8-9.7$ & $<0.001 *$ \\
\hline $\begin{array}{l}\text { *indicates statistical signifi } \\
\text { Functional Well-Being Moc } \\
\text { Hosmer \& Lemeshow Goo } \\
\text { Cox \& Snell } R^{2}: 23.7 \% \text {; Nag } \\
\text { Receiver Operating Charac } \\
\text { Tolerance: } 0.960-0.981 ; \mathrm{VI}\end{array}$ & $\begin{array}{l}\text { Ice at } p \leq 0.05 \\
\chi^{2}(7, n=262)=70.792, p \leq 0.00 \\
\text { ss of Fit: } \chi^{2}(8)=6.200, p=0.62 \\
\text { erke } R^{2}: 31.6 \% \text {; Sensitivity: } 69.5 \\
\text { istic: } 0.778 \text { (95\% Cl: } 0.723-0.83 \\
.019-1.042\end{array}$ & ; Specificit & y: $70.2 \%$ & & & & & \\
\hline \multicolumn{9}{|c|}{ Table 8: Adjusted Multivariate Predictors of Poorer Outcomes for Functional Well-Being Among Colorectal Cancer Survivo } \\
\hline Characteristic & Predictor & B & SE & Wald & df & $\begin{array}{l}\text { Adjusted } \\
\text { OR }\end{array}$ & $95 \% \mathrm{Cl}$ & $p$ \\
\hline \multirow[t]{2}{*}{ Gender } & Female & & & & & Reference & & \\
\hline & Male & -0.969 & 0.326 & 8.812 & 1 & 0.4 & $0.2-0.7$ & $0.003^{*}$ \\
\hline \multirow{3}{*}{$\begin{array}{l}\text { Change in Employment } \\
\text { Status Since Diagnosis }\end{array}$} & Remained/Became Employed & & & 6.589 & 2 & Reference & & $0.037^{*}$ \\
\hline & Remained Unemployed & -0.714 & 0.380 & 3.532 & 1 & 0.5 & $0.2-1.0$ & 0.060 \\
\hline & Became Unemployed & 0.292 & 0.495 & 0.346 & 1 & 1.3 & $0.5-3.5$ & 0.556 \\
\hline \multirow[t]{2}{*}{ Chemotherapy } & No Chemotherapy & & & & & Reference & & \\
\hline & Any Chemotherapy & 0.825 & 0.325 & 6.443 & 1 & 2.3 & $1.2-4.3$ & $0.011^{*}$ \\
\hline \multirow[t]{2}{*}{ Disease Status } & In Remission & & & & & Reference & & \\
\hline & Any Active Disease & 1.431 & 0.452 & 10.043 & 1 & 4.2 & $1.7-10.1$ & $0.002^{*}$ \\
\hline \multirow[t]{3}{*}{ Stoma } & Never had a Stoma & & & 9.218 & 2 & Reference & & $0.010^{*}$ \\
\hline & Stoma Reversed & 1.076 & 0.370 & 8.453 & 1 & 2.9 & $1.4-6.1$ & $0.004^{*}$ \\
\hline & Stoma Present & 0.778 & 0.422 & 3.401 & 1 & 2.2 & $1.0-5.0$ & 0.065 \\
\hline \multirow[t]{2}{*}{ Comorbidities } & None & & & & & Reference & & \\
\hline & One or More & 0.785 & 0.399 & 3.877 & 1 & 2.2 & $1.0-4.8$ & $0.049 *$ \\
\hline Private Health Insurance & Yes & & & & & Reference & & \\
\hline
\end{tabular}

This is the Accepted Manuscript of an article published by Elsevier in the International Journal of Nursing Studies on September 13th, 2019. The Version of Record of this manuscript is available online: DOI: https://doi.org/10.1016/j.ijnurstu.2019.103434. 
Authors Original Manuscript, accepted for publication in the International Journal of Nursing Studies on September $13^{\text {th }}, 2019$.

\begin{tabular}{|c|c|c|c|c|c|c|c|c|}
\hline & No & 0.734 & 0.324 & 5.147 & 1 & 2.1 & $1.1-3.9$ & $0.023^{*}$ \\
\hline \multirow{2}{*}{$\begin{array}{l}\text { Access to a Named Doctor } \\
\text { for Cancer-Related Worries }\end{array}$} & Yes & & & & & \multicolumn{2}{|l|}{ Reference } & \\
\hline & No & 0.863 & 0.388 & 4.939 & 1 & 2.4 & 1.1-5.1 & $0.026^{*}$ \\
\hline \multirow[t]{2}{*}{ Social Difficulties } & None & & & & & \multicolumn{2}{|l|}{ Reference } & \\
\hline & One or More & 1.123 & 0.335 & 11.233 & 1 & 3.1 & $1.6-5.9$ & $0.001^{*}$ \\
\hline \multicolumn{9}{|c|}{$*_{\text {indicates statistical significance at } p \leq 0.05}$} \\
\hline \multicolumn{9}{|c|}{ Colorectal Cancer Concerns Model: $\chi^{2}(11, n=240)=71.231, p \leq 0.001$} \\
\hline \multicolumn{9}{|c|}{ Hosmer \& Lemeshow Goodness of Fit: $\chi^{2}(8)=6.516, p=0.590$} \\
\hline \multicolumn{9}{|c|}{ Cox \& Snell $R^{2}: 25.7 \%$; Nagelkerke $R^{2}: 34.4 \%$; Sensitivity: $69.4 \%$; Specificity: $75.0 \%$} \\
\hline \multicolumn{9}{|c|}{ Receiver Operating Characteristic: 0.793 (95\% Cl: 0.736-0.849) } \\
\hline \multicolumn{9}{|c|}{ Tolerance: 0.901-0.971; VIF: 1.030-1.110 } \\
\hline
\end{tabular}

Table 9: Adjusted Multivariate Predictors of Poorer Outcomes for Colorectal Cancer-Specific Well-Being Among Colorectal Cancer Survivors

\section{Overall Quality of Life}

Participants who lived alone, had active disease or had undergone a stoma reversal were more likely to report lower quality of life. Social difficulties demonstrated the most significant association with quality of life. Absence of private health insurance and lower satisfaction with continuity of care were related to lower quality of life scores. Colorectal cancer survivors who attended cancer support services were more likely to report lower quality of life scores (Table 10).

\begin{tabular}{|c|c|c|c|c|c|c|c|c|}
\hline Characteristic & Predictor & B & SE & Wald & df & $\begin{array}{l}\text { Adjusted } \\
\text { OR }\end{array}$ & $95 \% \mathrm{Cl}$ & $p$ \\
\hline \multirow[t]{2}{*}{ Living Alone } & No & & & & & Reference & & \\
\hline & Yes & 0.982 & 0.438 & 5.039 & 1 & 2.7 & $1.1-6.3$ & $0.025^{*}$ \\
\hline \multirow[t]{2}{*}{ Disease Status } & In Remission & & & & & Reference & & \\
\hline & Any Active Disease & 1.331 & 0.485 & 7.537 & 1 & 3.8 & $1.5-9.8$ & $0.006 *$ \\
\hline \multirow[t]{3}{*}{ Stoma } & Never had a Stoma & & & 11.816 & 2 & Reference & & $0.003^{*}$ \\
\hline & Stoma Reversed & 1.388 & 0.404 & 11.805 & 1 & 4.0 & $1.8-8.8$ & $0.001 *$ \\
\hline & Stoma Present & 0.486 & 0.423 & 1.320 & 1 & 1.6 & $0.7-3.7$ & 0.251 \\
\hline \multirow[t]{2}{*}{ Private Health Insurance } & Yes & & & & & Reference & & \\
\hline & No & 0.757 & 0.332 & 5.185 & 1 & 2.1 & $1.1-4.1$ & $0.023 *$ \\
\hline \multirow{2}{*}{$\begin{array}{l}\text { Level of Satisfaction with } \\
\text { Continuity of Care }\end{array}$} & Satisfied & & & & & Reference & & \\
\hline & Some Dissatisfaction & 0.705 & 0.338 & 4.357 & 1 & 2.0 & $1.0-3.9$ & $0.037^{*}$ \\
\hline \multirow{2}{*}{$\begin{array}{l}\text { Access to a Named Doctor } \\
\text { for Cancer-Related Worries }\end{array}$} & Yes & & & & & Reference & & \\
\hline & No & 0.675 & 0.404 & 2.799 & 1 & 2.0 & $0.9-4.3$ & 0.094 \\
\hline \multirow{2}{*}{$\begin{array}{l}\text { Accessed Voluntary } \\
\text { Cancer Support Services }\end{array}$} & No & & & & & Reference & & \\
\hline & Yes & 0.968 & 0.479 & 4.082 & 1 & 2.6 & $1.0-6.7$ & $0.043 *$ \\
\hline \multirow[t]{2}{*}{ Social Difficulties } & None & & & & & Reference & & \\
\hline & One or More & 2.273 & 0.391 & 33.721 & 1 & 9.7 & $4.5-20.9$ & $<0.001 *$ \\
\hline \multicolumn{9}{|c|}{ *indicates statistical significance at $p \leq 0.05$} \\
\hline \multicolumn{9}{|c|}{ Quality of Life (FACTC) Model: $\chi^{2}(9, n=239)=94.886, p \leq 0.001$} \\
\hline \multicolumn{9}{|c|}{ Hosmer \& Lemeshow Goodness of Fit: $\chi^{2}(8)=3.726, p=0.881$} \\
\hline \multicolumn{9}{|c|}{ Cox \& Snell $R^{2}: 32.8 \%$; Nagelkerke $R^{2}: 43.7 \%$; Sensitivity: $75.4 \%$; Specificity: $74.4 \%$} \\
\hline \multicolumn{9}{|c|}{ Receiver Operating Characteristic: 0.836 (95\% Cl: 0.787-0.886) } \\
\hline \multicolumn{9}{|c|}{ Tolerance: $0.883-0.965$; VIF: $1.037-1.132$} \\
\hline
\end{tabular}

Table 10: Adjusted Multivariate Predictors of Poorer Outcomes for Overall Quality of Life Among Colorectal Cancer Survivors

This is the Accepted Manuscript of an article published by Elsevier in the International Journal of Nursing Studies on September 13th, 2019. The Version of Record of this manuscript is available online: DOI: https://doi.org/10.1016/j.ijnurstu.2019.103434. 
Authors Original Manuscript, accepted for publication in the International Journal of Nursing Studies on September 13 $3^{\text {th }}, 2019$.

\section{Discussion}

This paper suggests that healthcare-related variables are consistently associated with colorectal cancer survivors' quality of life in all domains of the FACT-C, aligning with the Ashing-Giwa (2005) Contextual Model of Health-Related Quality of Life. The finding that greater social difficulty and absence of private health insurance are associated with poorer quality of life in multiple domains adds to the body of evidence highlighting the relationship between healthcare disparities, greater social deprivation and poorer quality of life (Ashing-Giwa and Lim, 2008, Chambers et al., 2012, Sharp et al., 2018). Satisfaction with continuity of care was consistently associated with quality of life outcomes. Therefore, the limited importance of hospital-based support, access to named professionals, cancer survivorship care plans and treatment summaries for quality of life outcomes in this study are of interest.

The finding that access to a named nurse was related to emotional well-being lends support to evidence suggesting that access to an oncology professional could positively influence survivors' fear of recurrence and adaptation following treatment (Appleton et al., 2013, Taylor et al., 2011). More than four-fifths of participants had access to a named doctor or nurse and appeared to have predominantly sourced support from hospital-based professionals. While this finding may partially explain the absence of a relationship between quality of life and survivors' perceptions of support from hospital staff, it points towards dependence on oncology professionals for information and support. Cancer survivors' concerns that primary care practitioners lack knowledge and expertise to manage cancer-related issues are well-documented (Brandenbarg et al., 2017, Hudson et al., 2012, Murchie et al., 2016, Roorda et al., 2015). However, more than one-fifth of those who sought support from primary care and community services staff reported inadequate assistance from these settings. National and international policy directives call for greater integration of primary care and community services in cancer survivorship care (Department of Health, Ireland 2017, European CanCer Organisation, 2017, Institute of Medicine, 2006, McCabe et al., 2013, Warde et al., 2014). The findings of the current study suggest further resources may be necessary to assist primary care and community services to support survivors with cancer-related issues before this vision can be successfully realised.

In interpreting the results relating to cancer survivors' access to healthcare professionals and support in survivorship, the structure and funding model of the Irish health services must also be considered. In the Irish public health sector, follow-up care is predominantly nurse-led, while in the private sector it is physician-led. Having access to a named doctor was associated with more positive social and colorectal cancer-specific well-being. Having access to a doctor for information and

This is the Accepted Manuscript of an article published by Elsevier in the International Journal of Nursing Studies on September 13th, 2019. The Version of Record of this manuscript is available online: DOI: https://doi.org/10.1016/j.ijnurstu.2019.103434. 
Authors Original Manuscript, accepted for publication in the International Journal of Nursing Studies on September 13 $3^{\text {th }}, 2019$.

support within the public sector may be an additional source of support for survivors engaged in nurse-led models of care, while having access to nurses within physician-led models of care in private healthcare settings may have a similar effect. However, this hypothesis cannot be conclusively determined within the current study due to the mixed public-private model of healthcare provision operated in Ireland. It would be of interest to examine whether these findings are replicated in larger samples of survivors who receive follow-up care in exclusively private or public healthcare settings in future studies.

Cancer survivorship care plans and treatment summaries have been tentatively suggested as a possible solution to communication difficulties between primary and secondary care and cancer survivors (Appleton et al., 2013, Institute of Medicine, 2006). Although these documents were not a part of routine care in the participating healthcare settings, one-third of participants reported having one or both documents. Formal treatment summaries and survivorship care plans may support communication, dissemination of information and coordination of care between interdisciplinary healthcare professionals and cancer survivors (Brothers et al., 2013, Mayer et al., 2012, Nicolaije et al., 2015). The findings of this study reflect those of previous studies which suggest cancer survivorship care plans at best, do not affect quality of life outcomes or perceptions of care continuity and coordination (Boekhout et al., 2015, Brennan et al., 2014, Brothers et al., 2013, Grunfeld et al., 2011). At worst, survivorship care plans have been associated with greater symptom burden and emotional distress (Nicolaije et al., 2015). There is a need for significant innovation in the field to ensure survivorship care plans are part of a more extensive supportive care package that comprehensively responds to the specific challenges experienced by cancer survivors. Most critically, supportive care packages for cancer survivors must promote optimal continuity of care, ensuring referral to appropriate supports to address cancer-related social difficulties and unmet information and supportive care needs.

This study highlights the underuse of advocacy-led cancer support services. Cancer support services in Ireland are predominantly provided by the voluntary sector, independent of the healthcare sector. This model of provision contributes to inconsistencies in access and referral to support nationally (Department of Health, Ireland 2017, Warde et al., 2014). Notably, attending cancer support services was associated with poorer physical, colorectal cancer-specific and overall quality of life for this sample. It is impossible to ascertain whether participants who accessed cancer support services did so because they experienced poorer quality of life or unmet information and supportive care needs. Although cancer support groups may enhance survivors' social support (Rudy et al., 2001, Vos et al., 2004), participation has been associated with greater cancer-related distress (Grande et al., 2006).

This is the Accepted Manuscript of an article published by Elsevier in the International Journal of Nursing Studies on September 13th, 2019. The Version of Record of this manuscript is available online: DOI: https://doi.org/10.1016/j.ijnurstu.2019.103434. 
Authors Original Manuscript, accepted for publication in the International Journal of Nursing Studies on September 13 $3^{\text {th }}, 2019$.

These findings warrant further examination, as they suggest that there are factors affecting colorectal cancer survivors' quality of life which do not appear to be addressed by cancer support services nor specialist oncology services.

More than two-thirds of this sample reported one or more unmet information needs. Existing qualitative literature suggests that unmet healthcare and information needs are detrimental to colorectal cancer survivors' recovery and well-being (Appleton et al., 2013, Beech et al., 2012, Johansson et al., 2014, Sun et al., 2014). However, in multivariate models, unmet information needs were associated with emotional well-being only. Given the high proportion of participants who reported access to a named doctor or nurse to discuss cancer-related concerns, it is possible that survivors had identified pathways to address potentially detrimental unmet needs. However, further research is necessary to clarify this assertion.

The results of multivariate analysis support the Ashing-Giwa (2005) Contextual Model of HealthRelated Quality of Life. The Ashing-Giwa (2005) Model has been used primarily to examine quality of life outcomes among ethnically and culturally diverse samples of female cancer survivors. However, this study suggests the Model may be applied to broader populations of cancer survivors in international contexts, particularly where disparities may arise within healthcare delivery models and social and economic policies. Furthermore, the findings suggest that the influence of healthcarerelated factors upon cancer survivors' quality of life outcomes may be just as important as that of demographic and health-related factors. Indeed, age, ethnicity and time since diagnosis were not associated with colorectal cancer survivors' quality of life in multivariate analysis, consistent with previous studies of colorectal cancer survivors (Chambers et al., 2012, Hornbrook et al., 2011, Krouse et al., 2009). Collectively, the findings suggest continuity of care and social difficulties may be more valuable areas for intervention to address shortcomings in survivors' quality of life outcomes, as they are consistently associated with quality of life across multiple domains.

\section{Study Strengths and Limitations}

This study is one of the first to evaluate how healthcare experiences, including access to healthcare professionals, support from healthcare services and continuity of follow-up care may influence the quality of life of colorectal cancer survivors. While this survey achieved a reasonable response rate, with participants recruited from a population-based sample across multiple sites serving various socio-economic groups, the study is not without limitations. Firstly, the healthcare-related variables reported in this study are based on self-reported measures rather than observation. Secondly, positively skewed scores on the PCCQ and positive responses to questions of access and perceptions of support may indicate socially desirable responses. Thirdly, the continuous variables on the FACT-

This is the Accepted Manuscript of an article published by Elsevier in the International Journal of Nursing Studies on September 13th, 2019. The Version of Record of this manuscript is available online: DOI: https://doi.org/10.1016/j.ijnurstu.2019.103434. 
Authors Original Manuscript, accepted for publication in the International Journal of Nursing Studies on September 13 $3^{\text {th }}, 2019$.

C, PCCQ and SDI were skewed and demonstrated ceiling effects. The dichotomisation of FACT-C scores based on the sample median for each subscale limits the generalisability of the data. Finally, there was significant variation in the size of samples recruited at each site, with a larger proportion receiving follow-up care within public hospitals. It is not possible to ascertain whether the respondents recruited from the private hospital site or via cancer support services are representative of the broader population of colorectal cancer survivors receiving care or support in similar organisations in Ireland. Therefore, the results of this study must be interpreted with consideration of these limitations.

\section{Conclusions}

This study advances the utility of the Ashing-Giwa (2005) Contextual Model of Health-Related Quality of Life with heterogeneous populations of cancer survivors. This study highlights the potential importance of healthcare experiences for colorectal cancer survivors' quality of life outcomes. Greater social difficulty, lower satisfaction with continuity of care and health insurance status were the factors most consistently associated with poorer quality of life. While colorectal cancer survivors largely had access to support and information from oncology professionals, there were shortcomings in access and support received from professionals in community, primary care and cancer support settings. If primary care and community services are to be meaningfully integrated into the care and follow-up of cancer survivors, these developments must incorporate education and training for healthcare professionals to enhance confidence and capacity to manage cancer survivorship issues.

As the population of cancer survivors increases, it is imperative that ongoing developments in cancer survivorship policy address the current siloed approaches to care between primary, tertiary and advocacy sectors to optimise the continuity and location of cancer survivorship care. Such outcomes may only be achieved through strategic collaborations between organisations with vested interests in cancer survivorship to develop effective multi-agency interventions which empower cancer survivors to develop self-management skills and access the services which most effectively address unmet needs.

Given the limited evidence surrounding cancer survivorship care plans, policymakers and developers must remain cognizant of their current limitations to affect quality of life. While further work is necessary to ensure that survivorship care plans are truly person-centred and responsive to the challenges of cancer survivorship, recommendations for research and clinical practice must move beyond the myopic view that they may improve patient outcomes in isolation. Future innovations in practice to improve outcomes in cancer survivorship must consider the utility of care plans within

This is the Accepted Manuscript of an article published by Elsevier in the International Journal of Nursing Studies on September 13th, 2019. The Version of Record of this manuscript is available online: DOI: https://doi.org/10.1016/j.ijnurstu.2019.103434. 
Authors Original Manuscript, accepted for publication in the International Journal of Nursing Studies on September 13 $3^{\text {th }}, 2019$.

supportive care programmes which aim to optimise models of care, assessment of unmet needs, health system navigation and access to appropriate information and supportive care relative to the survivors' position in the cancer trajectory. In the context of the current study, we suggest continuity of care and identification of appropriate care pathways to ameliorate cancer survivors' social difficulties may be meaningful targets for interventions seeking to modify cancer survivors' quality of life outcomes.

\section{Conflicts of Interest}

SP and AMB report no conflict of interest. AD's time was funded by the Health Research Board Research Training Fellowship at the School of Nursing and Midwifery Trinity College Dublin. The authors alone are responsible for the content and writing of this paper.

\section{Funding}

This research was funded by the Health Research Board Research Training Fellowship 2014 (grant number HPF.2014.715). The Health Research Board had no role in the design of the study, the collection, analysis or interpretation of data, nor the writing of this paper.

\section{Acknowledgements}

This research was funded by the Health Research Board Research Training Fellowship 2014 (grant number HPF.2014.715). The authors would like to thank the physicians, nurses and staff at the colorectal cancer Surgery and Medical Oncology Departments of the participating hospitals, and the voluntary cancer support services who facilitated data collection.

This is the Accepted Manuscript of an article published by Elsevier in the International Journal of Nursing Studies on September 13th, 2019. The Version of Record of this manuscript is available online: DOI: https://doi.org/10.1016/j.ijnurstu.2019.103434. 
Authors Original Manuscript, accepted for publication in the International Journal of Nursing Studies on September $13^{\text {th }}, 2019$.

\section{References}

Appleton, L., Goodlad, S., Irvine, F., Poole, H., Wall, C., 2013. Patients' experiences of living beyond colorectal cancer: a qualitative study. European Journal of Oncology Nursing 17 (5), 610-617. DOI: https://doi.org/10.1016/j.ejon.2013.01.002.

Ashing-Giwa, K.T., 2005. The contextual model of HRQoL: A paradigm for expanding the HRQoL framework. Quality of Life Research 14 (2), 297-307. DOI: https://doi.org/10.1007/s11136004-0729-7.

Ashing-Giwa, K.T., Lim, J.W., 2011. Health-related quality of life outcomes among cervical cancer survivors: examining ethnic and linguistic differences. Cancer Epidemiology 35 (2), 194-201. DOI: https://doi.org/10.1016/i.canep.2010.06.006.

Ashing-Giwa, K.T., Lim, J.W., 2008. Predicting health-related quality of life: Testing the Contextual Model using structural equation modeling. Applied Research in Quality of Life 3 (3), 215-230. DOI: https://doi.org/10.1007/s11482-009-9057-y.

Ashing-Giwa, K.T., Tejero, J.S., Kim, J., Padilla, G.V., Kagawa-Singer, M., Tucker, M.B., Lim, J.W., 2009. Cervical cancer survivorship in a population based sample. Gynecologic Oncology 112 (2), 358-364. DOI: https://doi.org/10.1016/i.ygyno.2008.11.002.

Beech, N., Arber, A., Faithfull, S., 2012. Restoring a sense of wellness following colorectal cancer: a grounded theory. Journal of Advanced Nursing 68 (5), 1134-1144. DOI: https://doi.org/10.1111/j.1365-2648.2011.05820.x.

Boekhout, A.H., Maunsell, E., Pond, G.R., Julian, J.A., Coyle, D., Levine, M.N., Grunfeld, E., 2015. A survivorship care plan for breast cancer survivors: extended results of a randomized clinical trial. Journal of Cancer Survivorship 9 (4), 683. DOI: https://doi.org/10.1007/s11764-0150443-1.

Brandenbarg, D., Roorda, C., Stadlander, M., de Bock, G.H., Berger, M.Y., Berendsen, A.J., 2017. Patients' views on general practitioners' role during treatment and follow-up of colorectal cancer: A qualitative study. Family Practice 34 (2), 234-238. DOI: https://doi.org/10.1093/fampra/cmw124.

Brennan, M.E., Gormally, J.F., Butow, P., Boyle, F.M., Spillane, A.J., 2014. Survivorship care plans in cancer: a systematic review of care plan outcomes. British Journal of Cancer 111 (10), 18991908. DOI: https://doi.org/10.1038/bjc.2014.505.

Brothers, B.M., Easley, A., Salani, R., Andersen, B.L., 2013. Do survivorship care plans impact patients' evaluations of care? A randomized evaluation with gynecologic oncology patients. Gynecologic Oncology 129 (3), 554-558. DOI: https://doi.org/10.1016/j.ygyno.2013.02.037.

Chambers, S.K., Meng, X., Youl, P., Aitken, J., Dunn, J., Baade, P., 2012. A five-year prospective study of quality of life after colorectal cancer. Quality of Life Research 21 (9), 1551-1564. DOI: http://dx.doi.org/10.1007/s11136-011-0067-5.

Department of Health Ireland, 2017. National Cancer Strategy 2017-2026. Department of Health, Dublin, Ireland. Retrieved from: http://health.gov.ie/wpcontent/uploads/2017/07/National-Cancer-Strategy-2017-2026.pdf on 27/11/2018.

Department of Health United Kingdom, 2010. National cancer patient experiences survey programme: 2010 national survey report. Retrieved from: https://www.gov.uk/government/uploads/system/uploads/attachment data/file/216682/d h 122520.pdf on 27/11/2018.

Di Fabio, F., Koller, M., Nascimbeni, R., Talarico, C., Salerni, B., 2008. Long-term outcome after colorectal cancer resection. Patients' self-reported quality of life, sexual dysfunction and surgeons' awareness of patients' needs. Tumori 94 (1), 30-35. DOI: https://doi.org/10.1177/030089160809400107.

Doyle, N., 2008. Cancer survivorship: evolutionary concept analysis. Journal of Advanced Nursing 62 (4), 499-509. DOI: http://dx.doi.org/10.1111/j.1365-2648.2008.04617.x.

This is the Accepted Manuscript of an article published by Elsevier in the International Journal of Nursing Studies on September 13th, 2019. The Version of Record of this manuscript is available online: DOI: https://doi.org/10.1016/j.ijnurstu.2019.103434. 
Authors Original Manuscript, accepted for publication in the International Journal of Nursing Studies on September $13^{\text {th }}, 2019$.

Drury, A., Payne, S., Brady, A.M., 2017. Cancer Survivorship: Advancing the concept in the context of colorectal cancer. European Journal of Oncology Nursing 29, 135-147. DOI: http://dx.doi.org/10.1016/i.ejon.2017.06.006.

European CanCer Organisation, 2017. Integrated cancer care: Bringing primary care and secondary care together. Retrieved from: http://www.oeci.eu/Attachments/ECCO Position Statement Integrated Cancer Care.pdf on $27 / 11 / 2018$.

Grande, G.E., Myers, L.B., Sutton, S.R., 2006. How do patients who participate in cancer support groups differ from those who do not? Psycho-Oncology 15 (4), 321-334. DOI: https://doi.org/10.1002/pon.956.

Grunfeld, E., Julian, J.A., Pond, G., Maunsell, E., Coyle, D., Folkes, A., Joy, A.A., Provencher, L., Rayson, D., Rheaume, D.E., Porter, G.A., Paszat, L.F., Pritchard, K.I., Robidoux, A., Smith, S., Sussman, J., Dent, S., Sisler, J., Wiernikowski, J., Levine, M.N., 2011. Evaluating survivorship care plans: Results of a randomized, clinical trial of patients with breast cancer. Journal of Clinical Oncology 29 (36), 4755-4762. DOI: https://doi.org/10.1200/jco.2011.36.8373.

Hadjistavropoulos, H., Biem, H., Sharpe, D., Bourgault-Fagnou, M., Janzen, J., 2008. Patient perceptions of hospital discharge: Reliability and validity of a patient continuity of care questionnaire. International Journal for Quality in Health Care 20 (5), 314-323. DOI: https://doi.org/10.1093/intqhc/mzn030.

Haggstrom, D.A., Arora, N.K., Helft, P., Clayman, M.L., Oakley-Girvan, I., 2009. Follow-up care delivery among colorectal cancer survivors most often seen by primary and subspecialty care physicians. Journal of General Internal Medicine 24 Suppl 2, S472-479. DOI: http://doi.org/10.1007/s11606-009-1017-6.

Harrington, C.B., Hansen, J.A., Moskowitz, M., Todd, B.L., Feuerstein, M., 2010. It's not over when it's over: Long-term symptoms in cancer survivors - a systematic review. The International Journal of Psychiatry in Medicine 40 (2), 163-181. DOI: https://doi.org/10.2190/PM.40.2.c.

Hornbrook, M.C., Wendel, C.S., Coons, S.J., Grant, M., Herrinton, L.J., Mohler, M.J., Baldwin, C.M., McMullen, C.K., Green, S.B., Altschuler, A., Rawl, S.M., Krouse, R.S., 2011. Complications among colorectal cancer survivors: SF-6D preference-weighted quality of life scores. Medical Care 49 (3), 321-326. DOI: https://doi.org/10.1097/MLR.0b013e31820194c8.

Hudson, S.V., Miller, S.M., Hemler, J., Ferrante, J.M., Lyle, J., Oeffinger, K.C., DiPaola, R.S., 2012. Adult cancer survivors discuss follow-up in primary care: 'Not what i want, but maybe what i need'. Annals of Family Medicine 10 (5), 418-427. DOI: https://doi.org/10.1370/afm.1379.

Institute of Medicine, 2006. From cancer patient to cancer survivor: Lost in transition. Retrieved from: https://www.nap.edu/download/11468 on 27/11/2018.

Johansson, A.C., Axelsson, M., Berndtsson, I., Brink, E., 2014. Illness perceptions in relation to experiences of contemporary cancer care settings among colorectal cancer survivors and their partners. International Journal of Qualitative Studies on Health and Well-Being 9 (23581), 1-11. DOI: https://doi.org/10.3402/qhw.v9.23581.

Khan, N.F., Rose, P.W., Evans, J., 2012. Defining cancer survivorship: a more transparent approach is needed. Journal of Cancer Survivorship 6 (1), 33-36. DOI: https://doi.org/10.1007/s11764011-0194-6.

Krouse, R.S., Herrinton, L.J., Grant, M., Wendel, C.S., Green, S.B., Mohler, M.J., Baldwin, C.M., McMullen, C.K., Rawl, S.M., Matayoshi, E., Coons, S.J., Hornbrook, M.C., 2009. Healthrelated quality of life among long-term rectal cancer survivors with an ostomy: manifestations by sex. Journal of Clinical Oncology 27 (28), 4664-4670. DOI: https://doi.org/10.1200/ico.2008.20.9502.

Leigh, S., 2007. Cancer survivorship: A nursing perspective. In: Ganz, P.A. (Ed.), Cancer Survivorship. Springer, New York, pp. 8-13.

This is the Accepted Manuscript of an article published by Elsevier in the International Journal of Nursing Studies on September 13th, 2019. The Version of Record of this manuscript is available online: DOI: https://doi.org/10.1016/j.ijnurstu.2019.103434. 
Authors Original Manuscript, accepted for publication in the International Journal of Nursing Studies on September 13 $3^{\text {th }}, 2019$.

Mayer, D.K., Gerstel, A., Leak, A.N., Smith, S.K., 2012. Patient and provider preferences for survivorship care plans. Journal of Oncology Practice 8 (4), e80-e86. DOI: https://doi.org/10.1200/iop.2011.000401.

McCabe, M.S., Bhatia, S., Oeffinger, K.C., Reaman, G.H., Tyne, C., Wollins, D.S., Hudson, M.M., 2013. American Society of Clinical Oncology statement: achieving high-quality cancer survivorship care. Journal of Clinical Oncology 31 (5), 631-640. DOI: https://doi.org/10.1200/JCO.2012.46.6854.

McCaughan, E., Prue, G., Parahoo, K., Mcllfatrick, S., McKenna, H., 2012. Exploring and comparing the experience and coping behaviour of men and women with colorectal cancer after chemotherapy treatment: a qualitative longitudinal study. Psycho-Oncology 21 (1), 64-71. DOI: https://doi.org/10.1002/pon.1871.

McDougall, J.A., Blair, C.K., Wiggins, C.L., Goodwin, M.B., Chiu, V.K., Rajput, A., Kinney, A.Y., 2019. Socioeconomic disparities in health-related quality of life among colorectal cancer survivors. Journal of Cancer Survivorship 13 (3), 459-467. DOI: http://doi.org/10.1007/s11764-01900767-9.

McMullen, C.K., Hornbrook, M.C., Grant, M., Baldwin, C.M., Wendel, C.S., Mohler, M.J., Altschuler, A., Ramirez, M., Krouse, R.S., 2008. The greatest challenges reported by long-term colorectal cancer survivors with stomas. The Journal of Supportive Oncology 6 (4), 175-182.

Mullen, F., 1985. Seasons of survivorship: Reflections of a physician with cancer. The New England Journal of Medicine 313 (25), 270-273. DOI: http://doi.org/10.1056/NEJM198507253130421.

Murchie, P., Norwood, P.F., Pietrucin-Materek, M., Porteous, T., Hannaford, P.C., M., R., 2016. Determining cancer survivors' preferences to inform new models of follow-up care. British Journal of Cancer 115 (12), 1495-1503. DOI: https://doi.org/10.1038/bjc.2016.352.

Nicolaije, K.A., Ezendam, N.P., Vos, M.C., Pijnenborg, J.M., Boll, D., Boss, E.A., Hermans, R.H., Engelhart, K.C., Haartsen, J.E., Pijlman, B.M., 2015. Impact of an automatically generated cancer survivorship care plan on patient-reported outcomes in routine clinical practice: longitudinal outcomes of a pragmatic, cluster randomized trial. Journal of Clinical Oncology 33 (31), 3550-3559. DOI: https://doi.org/10.1200/JCO.2014.60.3399.

Nikoletti, S., Young, J., Levitt, M., King, M., Chidlow, C., Hollingsworth, S., 2008. Bowel problems, selfcare practices, and information needs of colorectal cancer survivors at 6 to 24 months after sphincter-saving surgery. Cancer Nursing 31 (5), 389-398. DOI: https://doi.org/10.1097/01.NCC.0000305759.04357.1b.

O'Shea, M.T., Collins, C., 2016. Access to diagnostics used to detect cancer. Irish College of General Practitioners, Dublin, Ireland. Retrieved from: http://hdl.handle.net/10147/615148 $27 / 11 / 2018$.

Quality Health, 2012. Quality of life of cancer survivors in england: Report on a pilot survey using patient reported outcome measures (PROMS). Department of Health, United Kingdom. Retrieved from: https://assets.publishing.service.gov.uk/government/uploads/system/uploads/attachment data/file/267042/9284-TSO-2900701-PROMS-1.pdf on 27/11/2018.

Ramirez, M., McMullen, C., Grant, M., Altschuler, A., Hornbrook, M.C., Krouse, R.S., 2009. Figuring out sex in a reconfigured body: Experiences of female colorectal cancer survivors with ostomies. Women \& Health 49 (8), 608-624. DOI: https://doi.org/10.1080/03630240903496093.

Reuben, S.H., 2004. Living Beyond Cancer: Finding a New Balance. President's Cancer Panel 20032004 Annual Report. The President's Cancer Panel, Bethesda. Retrieved from: https://pubs.cancer.gov/ncipl/detail.aspx?prodid=P986 on 27/11/2018.

Roorda, C., de Bock, G.H., Scholing, C., van der Meer, K., Berger, M.Y., de Fouw, M., Berendsen, A.J., 2015. Patients' preferences for post-treatment breast cancer follow-up in primary care vs.

This is the Accepted Manuscript of an article published by Elsevier in the International Journal of Nursing Studies on September 13th, 2019. The Version of Record of this manuscript is available online: DOI: https://doi.org/10.1016/j.ijnurstu.2019.103434. 
Authors Original Manuscript, accepted for publication in the International Journal of Nursing Studies on September 13 $3^{\text {th }}, 2019$.

secondary care: a qualitative study. Health Expectations 18 (6), 2192-2201. DOI: http://doi.org/10.1111/hex.12189.

Rowland, J.H., Kent, E.E., Forsythe, L.P., Loge, J.H., Hjorth, L., Glaser, A., Mattioli, V., Fosså, S.D., 2013. Cancer survivorship research in Europe and the United States: Where have we been, where are we going, and what can we learn from each other? Cancer 119 (S11), 2094-2108. DOI: http://dx.doi.org/10.1002/cncr.28060.

Rudy, R.R., Rosenfeld, L.B., Galassi, J.P., Parker, J., Schanberg, R., 2001. Participants' perceptions of a peer-helper, telephone-based social support intervention for melanoma patients. Health Communication 13 (3), 285-305. DOI: https://doi.org/10.1207/s15327027hc1303 4.

Sharp, L., O'Leary, E., O'Ceilleachair, A., Skally, M., Hanly, P., 2018. Financial impact of colorectal cancer and its consequences: Associations between cancer-related financial stress and strain and health-related quality of life. Diseases of the Colon and Rectum 61 (1), 27-35. DOI: http://doi.org/10.1097/dcr.0000000000000923.

Sisler, J.J., Taylor-Brown, J., Nugent, Z., Bell, D., Khawaja, M., Czaykowski, P., Wirtzfeld, D., Park, J., Ahmed, S., 2012. Continuity of care of colorectal cancer survivors at the end of treatment: the oncology-primary care interface. Journal of Cancer Survivorship 6 (4), 468-475. DOI: https://doi.org/10.1007/s11764-012-0235-9.

Sun, V., Grant, M., McMullen, C.K., Altschuler, A., Mohler, M.J., Hornbrook, M.C., Herrinton, L.J., Krouse, R.S., 2014. From diagnosis through survivorship: health-care experiences of colorectal cancer survivors with ostomies. Supportive Care in Cancer 22 (6), 1563-1570. DOI: https://doi.org/10.1007/s00520-014-2118-2.

Taylor, C., Richardson, A., Cowley, S., 2011. Surviving cancer treatment: an investigation of the experience of fear about, and monitoring for, recurrence in patients following treatment for colorectal cancer. European Journal of Oncology Nursing 15 (3), 243-249. DOI: http://doi.org/10.1016/i.ejon.2011.03.010.

Vos, P.J., Garssen, B., Visser, A.P., Duivenvoorden, H.J., de Haes, H.C., 2004. Psychosocial intervention for women with primary, non-metastatic breast cancer: a comparison between participants and non-participants. Psychotherapy and Psychosomatics 73 (5), 276-285. DOI: https://doi.org/10.1159/000078844.

Ward, W.L., Hahn, E.A., Mo, F., Hernandez, L., Tulsky, D.S., Cella, D., 1999. Reliability and validity of the Functional Assessment of Cancer Therapy-Colorectal (FACT-C) quality of life instrument. Quality of Life Research 8 (3), 181-195. DOI: https://doi.org/10.1023/A:1008821826499.

Warde, P., de Koning, H., Richardson, A., 2014. National Cancer Strategy 2006: A strategy for cancer control in Ireland, evaluation panel report. Retrieved from: http://health.gov.ie/wpcontent/uploads/2015/05/Final-Evaluation-Panel-Report-of-National-Cancer-Strategy2006.pdf on 27/11/2018.

Wright, P., Smith, A.B., Keding, A., Velikova, G., 2011. The Social Difficulties Inventory (SDI): development of subscales and scoring guidance for staff. Psycho-Oncology 20 (1), 36-43. DOI: http://doi.org/10.1002/pon.1705.

This is the Accepted Manuscript of an article published by Elsevier in the International Journal of Nursing Studies on September 13th, 2019. The Version of Record of this manuscript is available online: DOI: https://doi.org/10.1016/j.ijnurstu.2019.103434. 